\title{
Reference Values for Umbilical Artery Lactate by Mode of Delivery and Gestational Age: A Retrospective Observational Study
}

\author{
Vincent D. Gaertner ${ }^{\mathrm{a}}$ Dirk Bassler ${ }^{\mathrm{a}}$ Roland Zimmermann ${ }^{\mathrm{b}} \quad$ Jehudith R. Fontijn ${ }^{\mathrm{a}}$ \\ aDepartment of Neonatology, Newborn Research Zurich, University Hospital and University of Zurich, Zurich, Switzerland; \\ ${ }^{b}$ Department of Obstetrics and Gynecology, University Hospital and University of Zurich, Zurich, Switzerland
}

\section{Keywords}

Lactate $\cdot$ Arterial cord blood $\cdot$ Neonate $\cdot \mathrm{pH} \cdot$ Perinatal acidosis

\begin{abstract}
Introduction: Umbilical artery cord blood provides information about the intrauterine metabolism during labor. Umbilical artery lactate is a useful parameter in predicting neonatal morbidity, but data on normal values are limited. We aimed to provide reference ranges of umbilical artery lactate values across the combination of gestational age and mode of delivery. Methods: A single-center retrospective observational study of liveborn infants born between 23 and 42 completed weeks gestation was conducted. Lactate, base deficit (BD), and pH from arterial cord blood were assessed between June 2018 and November 2020 and compared across gestational ages and modes of delivery. Results: Overall, there were 3,353 infants with evaluable data. Lactate values at the 50th, 90th, and 97th percentile were 3.4, 7.0, and $9.0 \mathrm{mmol} / \mathrm{L}$. Lactate was inversely correlated with $\mathrm{pH}(r$ $=-0.77, p<0.001)$ and positively correlated with $\mathrm{BD}(r=0.63$, $p<0.001)$. Lactate values changed significantly across gestational age (Kruskal-Wallis test, $p<0.001)$ which was attrib-
\end{abstract}

karger@karger.com www.karger.com/neo

Karger $\stackrel{\text { ' }}{5}$

GOPEN ACCESS
(C) 2021 The Author(s)

Published by S. Karger AG, Basel

This is an Open Access article licensed under the Creative Commons Attribution-NonCommercial-4.0 International License (CC BY-NC) (http://www.karger.com/Services/OpenAccessLicense), applicable to the online version of the article only. Usage and distribution for commercial purposes requires written permission. utable to an increase in lactate at 39-41 weeks gestational age. Also, lactate values were different across modes of delivery (Kruskal-Wallis test, $p<0.001$ ) with lowest values in elective CS and highest values in vaginal instrumental deliveries. Comprehensive reference ranges across modes of delivery and gestational ages could be established. Discussion: Mode of delivery and gestational age contribute to lactate levels with highest values occurring in vaginal instrumental deliveries and between 39 and 41 weeks gestational age. Based on these observations, we provide detailed reference ranges for clinical use.

(c) 2021 The Author(s)

Published by S. Karger AG, Basel

\section{Introduction}

Umbilical artery cord blood provides information about the intrauterine metabolism during labor [1]. Acidosis is defined by a $\mathrm{pH}<7.35$ while base deficit (BD), partial pressure of carbon dioxide $\left(\mathrm{pCO}_{2}\right)$, and lactate indicate the origin of the acidosis [2]. The acid-base status is useful to ensure appropriately focused interventions in case of severe acidosis (i.e., $\mathrm{pH}<7.00$ and/or $\mathrm{BD}$ of $\geq 16.0$ $\mathrm{mmol} / \mathrm{L}$ ) and to predict increased morbidity and mortal- 
ity [3]. Lactate was superior to $\mathrm{pH}$ in predicting neonatal morbidity in case-control and prospective cohort studies [4-6], and sensitivity and specificity of umbilical artery lactate for neurological sequelae were $70 \%$ and $93 \%$, respectively [7, 8]. Reference ranges of lactate values in newborn infants would be useful in distinguishing infants who may need additional clinical examination, laboratory work, or intensive care monitoring.

Umbilical artery lactate after vaginal delivery increases gradually from 34 weeks gestational age onward [9]. In a small population of term infants, lactate values were highest in vaginal instrumental deliveries (VID) and lowest in elective cesarean section (eCS) [10]. However, increased umbilical artery lactate may reflect infant pathologies such as an incipient sepsis or cardiac anomalies. Comprehensive reference ranges across the combination of mode of delivery and gestational age may assist clinicians to integrate lactate values into clinical considerations.

Thus, we aimed to (1) assess the umbilical artery acidbase status and (2) provide combined reference ranges for umbilical artery lactate by gestational age and mode of delivery. We expected higher values in vaginal deliveries and emergency cesarean sections as well as an increase in lactate in more mature infants. Finally, we intended to (3) show the distribution of lactate values for healthy term infants separately who are cared for on the regular postnatal ward.

\section{Methods}

\section{Data Collection}

This was a retrospective observational study at the Department of Obstetrics and the Department of Neonatology of the University Hospital Zurich, a tertiary referral center with approximately 3,000 births per year. Umbilical artery cord blood is drawn as a routine measurement at our hospital for decades. In June 2018, our clinic started to store values electronically. Immediately after delivery, a midwife drew blood from the umbilical artery in a preheparinised syringe (safePICO Aspirator; Radiometer Medical ApS, Brønshøj, Denmark), and the blood was analyzed within 10 min using the ABL815 FLEX blood gas analyzer (Radiometer Medical ApS, Brønshøj, Denmark). Lactate, $\mathrm{pH}$, and $\mathrm{pCO}_{2}$ were measured directly by using the blood gas analyzer while $\mathrm{BD}$ was calculated based on the Henderson-Hasselbalch equation and the Siggaard-Andersen acid-base chart algorithm. Lactate was measured via amperometry using an electrode coated with lactate oxidase which converts lactate to pyruvate and hydrogen peroxide, and the resulting hydrogen peroxide is measured amperometrically [11]. Obstetric and neonatal data were collected and stored using the local patient management system and anonymized before analysis. All infants who were born between June 2018 (beginning of digital data collection) and November 2020 in the University Hospital Zurich were eligible for inclusion in the analysis. Infants were in- cluded if arterial cord blood data were available and mothers had provided a written informed general consent to allow use of their clinical and laboratory data for research purposes.

\section{Data Analysis}

First, we extracted values of acid-base status for all infants. Second, we assessed correlation between lactate, $\mathrm{pH}$, and BD. Third, we assessed lactate values for completed weeks of gestation (between 23 and 42 weeks). Fourth, we evaluated changes in lactate values across different modes of delivery. We predefined the following modes of delivery: spontaneous vaginal delivery, VID (i.e., forceps or vacuum extraction), eCS without prior contractions, and unplanned or emergency cesarean section after the onset of uterine contractions (uCS). We then assessed the correlation of arterial cord lactate with cardiotocogram (CTG) readings (based on the 2015 FIGO intrapartum CTG classification) in the opening and the expulsion stage of labor to evaluate the potential influence of prenatal factors. Fifth, for the calculation of reference ranges, infants were separated into generally acknowledged age groups (extremely preterm infants $\left[\leq 27^{6 / 7}\right.$ weeks], very preterm infants $\left[28^{0 / 7}-31^{6 / 7}\right.$ weeks $]$, moderately preterm infants $\left[32^{0 / 7}-33^{6 / 7}\right.$ weeks], late preterm infants $\left[34^{0 / 7}-36^{6 / 7}\right.$ weeks], and term born infants $\left[\geq 37^{0 / 7}\right.$ weeks]), and we calculated percentiles for each combination of gestational age groups and mode of delivery. Finally, we calculated percentiles for healthy term infants separately. We categorized infants as healthy if they did not receive additional monitoring during their hospital stay after assessment and examination by a pediatrician. Infants with a $\mathrm{pH}<7.0$ were always admitted to the neonatal unit and thus excluded from this subgroup.

\section{Statistical Analysis}

We calculated percentiles, including median and interquartile range (IQR), for each group of infants. Differences over gestational age groups and within the different modes of delivery were assessed using a Kruskal-Wallis test for the overall difference. In case of a significant global difference, we performed post hoc comparisons between separate groups (i.e., gestational age or mode of delivery) using pairwise Wilcoxon tests with Bonferroni-Holm correction for multiple testing. Correlation between separate parameters was assessed using Pearson's correlation. A $p$-value $<0.05$ was considered statistically significant.

\section{Results}

\section{Population}

Overall, 6,136 infants were born alive during the study period. Of these, 52 had to be excluded as no cord blood values were available and for 2,731 infants there was no general consent available, leaving 3,353 infants for primary analysis. Demographics and descriptive statistics of the population are provided in Table 1.

\section{Acid-Base Status}

Median (IQR) values for $\mathrm{pH}$, lactate, and $\mathrm{BD}$ are provided in Table 1. Across all infants, lactate values at the 
Table 1. Population characteristics including arterial cord blood values in all infants and in clinically healthy term infants

\begin{tabular}{lc}
\hline & $\begin{array}{c}\text { Included infants } \\
(N=3,353)\end{array}$ \\
\hline Population characteristics, median (range) & \\
Gestational age, weeks + days & $38^{6 / 7}\left(24^{0 / 7}-42^{1 / 7}\right)$ \\
Birth weight, $g$ & $3,200(450-4,870)$ \\
Male sex, $N(\%)$ & $1,719(51.3)$ \\
Obstetric information: mode of delivery, & $N(\%)$ \\
Spontaneous vaginal & $1,368(40.7)$ \\
Vaginal instrumental & $341(10.2)$ \\
Elective cesarean section & $909(27.1)$ \\
Unplanned cesarean section & $735(21.9)$ \\
Perinatal infant characteristics & \\
Apgar at 1 min & $8(0-10)$ \\
Apgar at 5 min & $9(1-10)$ \\
Apgar at 10 min & $9(1-10)$ \\
Arterial cord pH & $7.29(6.76-7.54)$ \\
Arterial cord lactate, mmol/L & $3.4(0.1-22.0)$ \\
Arterial cord base deficit, mmol/L & $2.3(-12.1$ to 27.8$)$ \\
\hline
\end{tabular}

Where not otherwise specified, median and range are provided.

$3 \mathrm{rd}, 10$ th, 90th, and 97th percentile were 1.0, 1.8, 7.0, and $9.0 \mathrm{mmol} / \mathrm{L}$, respectively. Mean $( \pm 1 z)$ lactate was at 4.0 $( \pm 2.3)$. There was a strong inverse correlation between lactate and $\mathrm{pH}(r=-0.77, p<0.001)$ as well as $\mathrm{BD}$ and $\mathrm{pH}$ $(r=-0.58, p<0.001)$ while lactate and BD correlated positively $(r=0.63, p<0.001$; Fig. 1$)$.

\section{Lactate Values across Gestational Age}

Lactate values changed significantly across gestational age (Kruskal-Wallis test for overall difference: $\chi^{2}=480$, $p<0.001$; Fig. 2). Post hoc analyses revealed that differences were mainly due to an increase in lactate at 39-41 weeks gestational age (online suppl. Table 2; see www. karger.com/doi/10.1159/000518748 for all online suppl. material).

\section{Lactate Values across Mode of Delivery}

Lactate values were significantly different between each of the 4 modes of delivery (Kruskal-Wallis test for overall difference: $\chi^{2}=1,241, p<0.001$; Fig. 3). Lowest lactate values were seen in eCS and highest values in VID (all $p<0.001$ in post hoc analyses; online suppl. Table 1 ). The range of lactate values was the highest in uCS reaching values $>20 \mathrm{mmol} / \mathrm{L}$. Lactate values were highly correlated with CTG readings during the expulsion stage $(r=0.33, p<0.001)$ but not during the opening stage of labor $(r=0.03, p=0.13)$.

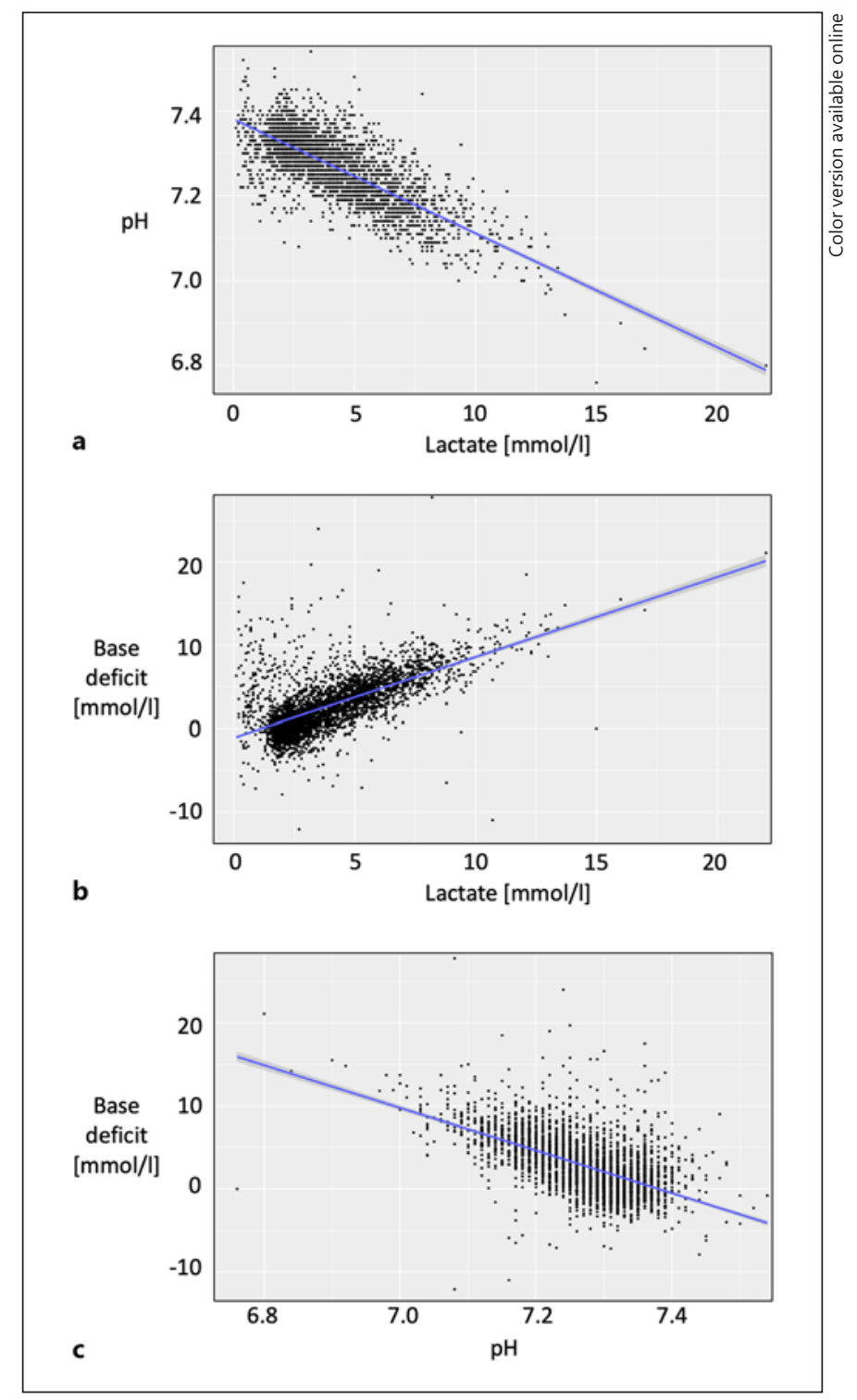

Fig. 1. Correlation between $\mathrm{pH}$, lactate, and base deficit. Dots indicate single patients. The blue line shows the linear regression line with standard errors plotted as gray error lines.

\section{Reference Ranges across Mode of Delivery and}

Gestational Age

Table 2 provides reference ranges by predefined gestational age groups as well as birth mode, and Figure 4 illustrates the changes.

\section{Lactate Values in Healthy Term Infants}

After exclusion of preterm infants and infants who were admitted to the neonatal ward, 2,656 infants remained for subgroup analysis of healthy term infants. For those infants, the lactate values at the $3 \mathrm{rd}, 10 \mathrm{th}, 90 \mathrm{th}$, and 
Fig. 2. Umbilical artery lactate values across weeks of gestational age.

Fig. 3. Umbilical artery lactate values across different modes of delivery. All comparisons between single modes of delivery were significantly different (all $p<0.001$ ). CS, cesarean section.
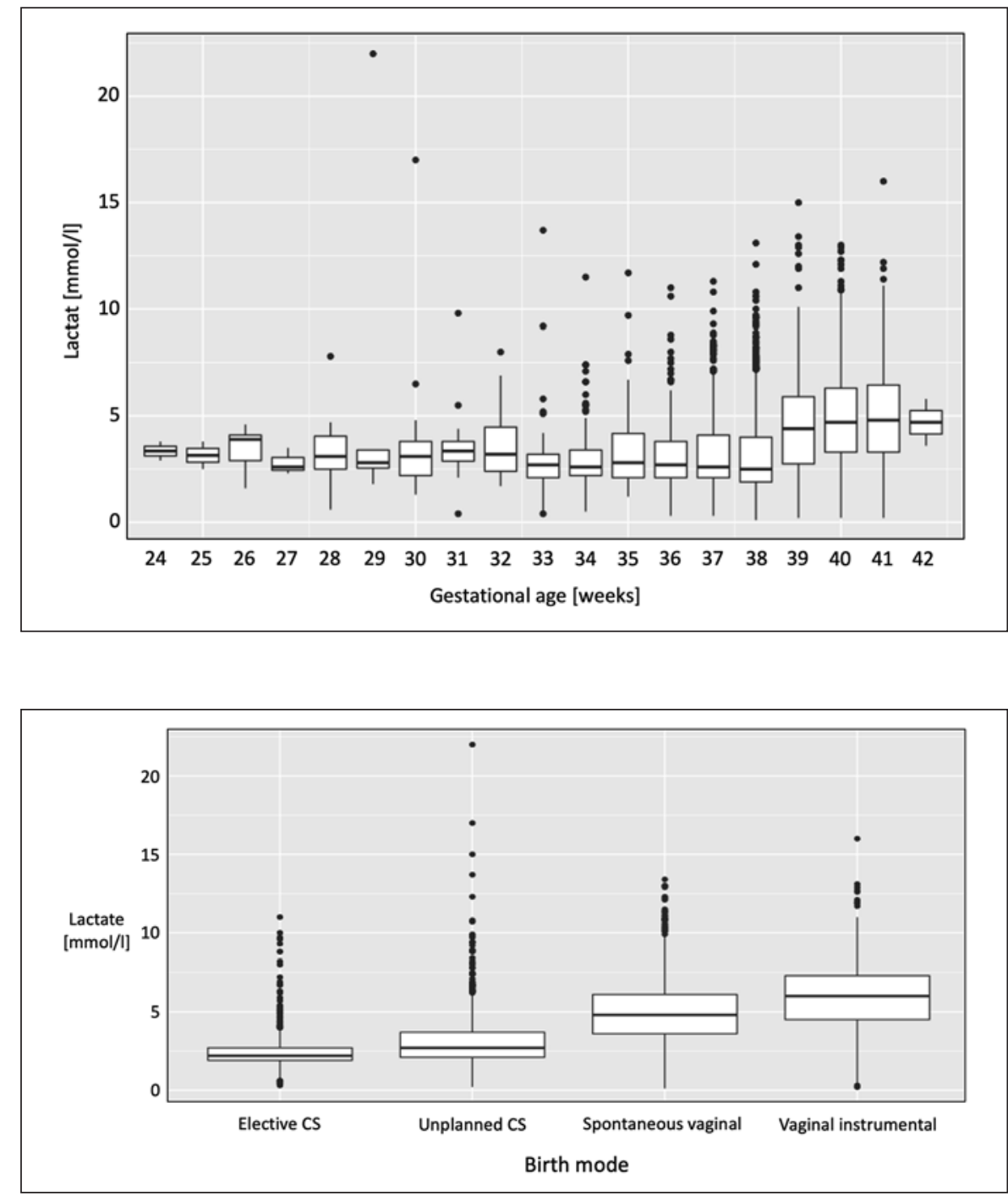

97th percentile were $1.0,1.7,7.2$, and $9.0 \mathrm{mmol} / \mathrm{L}$, respectively, and the mean $( \pm 1 z)$ was $4.1( \pm 2.2)$. For term infants admitted to the neonatal unit $(N=191)$, the lactate values at the 3rd, 10th, 90th, and 97th percentile were $0.8,1.8$, 7.4 , and $10.8 \mathrm{mmol} / \mathrm{L}$, respectively, and the mean $( \pm 1 z)$ was $4.3( \pm 2.8)$.

\section{Discussion}

This study comprehensively assesses umbilical artery lactate across gestational age as well as mode of delivery. We saw that lactate values were influenced by gestational age and mode of delivery: highest lactate values were seen in VID and in infants born between 39 and 41 weeks gestation. We provided detailed combined reference ranges for gestational age groups and modes of delivery for clinical use.

Increasing gestational age is associated with a mixed metabolic acidosis after birth [12]. Wiberg and colleagues [9] showed a gradual increase in umbilical artery lactate from 34 completed weeks gestation onward in vaginal deliveries. Opposed to these findings, we showed that the increase in lactate values is restricted to infants born between 39 and 41 completed weeks gestation. This difference may be due to the inclusion of VID in our study. Indeed, we demonstrated that lactate values in eCS remain comparable across gestational age, and thus the increased risk of metabolic acidosis in full term infants may be mostly due to mode of delivery.

We demonstrated that lactate values vary across different modes of delivery with an incremental increase from 
Table 2. Percentiles of lactate values across gestational age groups and mode of delivery

\begin{tabular}{|c|c|c|c|c|c|c|c|c|c|}
\hline \multirow[t]{2}{*}{ Group } & \multirow[t]{2}{*}{$N$} & \multicolumn{5}{|c|}{ Percentile } & \multicolumn{3}{|c|}{$z$-scores } \\
\hline & & $3 \mathrm{rd}$ & 10th & 50 th & 90th & 97 th & $-1 z$ & mean & $+1 z$ \\
\hline Extremely preterm & 14 & 1.8 & 2.2 & 3.6 & 4.2 & 4.5 & 2.3 & 3.3 & 4.2 \\
\hline Elective CS & 5 & 1.7 & 2.0 & 2.6 & 4.3 & 4.5 & 1.8 & 3.0 & 4.2 \\
\hline Unplanned CS & 9 & 2.1 & 2.3 & 3.7 & 4.0 & 4.2 & 2.6 & 3.4 & 4.1 \\
\hline Spontaneous vaginal & 0 & - & - & - & - & - & & & \\
\hline Vaginal instrumental & 0 & - & - & - & - & - & & & \\
\hline Very preterm & 53 & 1.0 & 2.1 & 3.2 & 5.4 & 13.0 & 0.4 & 3.9 & 7.4 \\
\hline Elective CS & 19 & 0.5 & 1.6 & 2.7 & 3.8 & 4.6 & 1.6 & 2.7 & 3.8 \\
\hline Unplanned CS & 31 & 2.0 & 2.3 & 3.4 & 7.8 & 17.5 & 0.3 & 4.6 & 9.0 \\
\hline Spontaneous vaginal & 3 & - & - & - & - & - & & & \\
\hline Vaginal instrumental & 0 & - & - & - & - & - & & & \\
\hline Moderately preterm & 63 & 0.8 & 1.6 & 2.8 & 5.4 & 8.2 & 1.2 & 3.3 & 5.4 \\
\hline Elective CS & 15 & 2.1 & 2.1 & 2.8 & 4.1 & 5.1 & 2.0 & 3.0 & 3.9 \\
\hline Unplanned CS & 41 & 0.6 & 1.2 & 2.8 & 5.2 & 7.7 & 0.9 & 3.2 & 5.5 \\
\hline Spontaneous vaginal & 6 & 2.1 & 2.3 & 4.3 & 8.1 & 8.9 & 2.0 & 4.9 & 7.7 \\
\hline Vaginal instrumental & 1 & - & - & - & - & - & & & \\
\hline Late preterm & 374 & 1.5 & 1.8 & 2.7 & 5.8 & 7.5 & 1.5 & 3.3 & 5.0 \\
\hline Elective CS & 119 & 1.4 & 1.7 & 2.4 & 3.5 & 4.6 & 1.6 & 2.6 & 3.6 \\
\hline Unplanned CS & 172 & 1.5 & 1.8 & 2.5 & 3.8 & 5.8 & 1.7 & 2.7 & 3.8 \\
\hline Spontaneous vaginal & 72 & 2.0 & 2.8 & 5.0 & 7.5 & 8.5 & 3.1 & 5.0 & 7.0 \\
\hline Vaginal instrumental & 11 & 3.5 & 3.9 & 6.1 & 11.0 & 11.5 & 4.2 & 7.1 & 9.9 \\
\hline Term born & 2,847 & 1.0 & 1.7 & 3.7 & 7.2 & 9.1 & 1.8 & 4.1 & 6.4 \\
\hline Elective CS & 751 & 1.4 & 1.6 & 2.2 & 3.3 & 5.2 & 1.3 & 2.4 & 3.6 \\
\hline Unplanned CS & 482 & 1.1 & 1.8 & 2.8 & 5.5 & 8.3 & 1.5 & 3.3 & 5.2 \\
\hline Spontaneous vaginal & 1,285 & 0.8 & 2.4 & 4.8 & 7.6 & 9.3 & 2.8 & 4.9 & 7.0 \\
\hline Vaginal instrumental & 329 & 1.1 & 3.3 & 6.0 & 8.8 & 11.0 & 3.5 & 6.0 & 8.4 \\
\hline
\end{tabular}

The 3rd, 10th, 50th, 90th, and 97th percentile as well as $z$-scores are shown. Only percentiles for groups of at least 5 infants are shown. All values are shown as millimoles per liter. CS, cesarean section.

eCS via unplanned CS and spontaneous vaginal to VID where lactate values were the highest. This is comparable to recent findings from smaller studies $[10,13]$. We propose 2 mechanisms for these findings: first, delayed cord clamping contributes to increased lactate by prolonging the time until blood sampling $[13,14]$, which may have contributed to higher values in vaginal deliveries. Second, various peripartal risk factors (e.g., uterine rupture, placental abruption, chorioamnionitis, and pre-eclampsia) may have contributed to higher lactate values. Indeed, this is substantiated by the correlation of arterial cord lactate with CTG readings during expulsion stage. Third, uterine contractions contribute to a surge in stress hormones [15], which is thought to assist in clearing fetal lung liquid thereby improving neonatal transition [16]. eCS is associated with less fetal stress, as indicated by the lowest lactate values in our cohort. However, the lack of uterine contractions may be associated with a higher risk for admission to NICU, mostly due to respiratory distress
[17]. This suggests that low lactate values are not necessarily desirable, and limited perinatal stress may be beneficial for the infant. In fact, there is an ongoing trial examining whether inducing mild fetal stress by administering oxytocin before eCS may reduce the admission rate of newborns [18]. However, trial results need to be awaited before firm conclusions of the potential benefit of mild fetal stress can be drawn.

Higher lactate values during instrumental vaginal and unplanned cesarean delivery may be explained by fetal distress during obstructed labor [19]. Interestingly, lactate values in unplanned CS were very variable with the upper range exceeding $20 \mathrm{mmol} / \mathrm{L}$. A permissive approach to managing the second stage of labor reduced the rate of CS at the cost of an increased rate of maternal (third- and fourth-degree lacerations) and neonatal (shoulder dystocia, admission to the NICU, and arterial cord $\mathrm{pH}<7.00$ ) morbidities [20]. Our data may provide some guidance for decision-making during labor based 
Fig. 4. Lactate values by gestational age and birth mode across all infants. The $x$-axis shows different gestational age groups, and colored boxplots indicate different modes of delivery as described in the legend in the upper right corner. Boxplots show median and interquartile range. eCS, elective cesarean section; uCS, unplanned or emergency cesarean section; SVD, spontaneous vaginal delivery; VID, vaginal instrumental delivery.

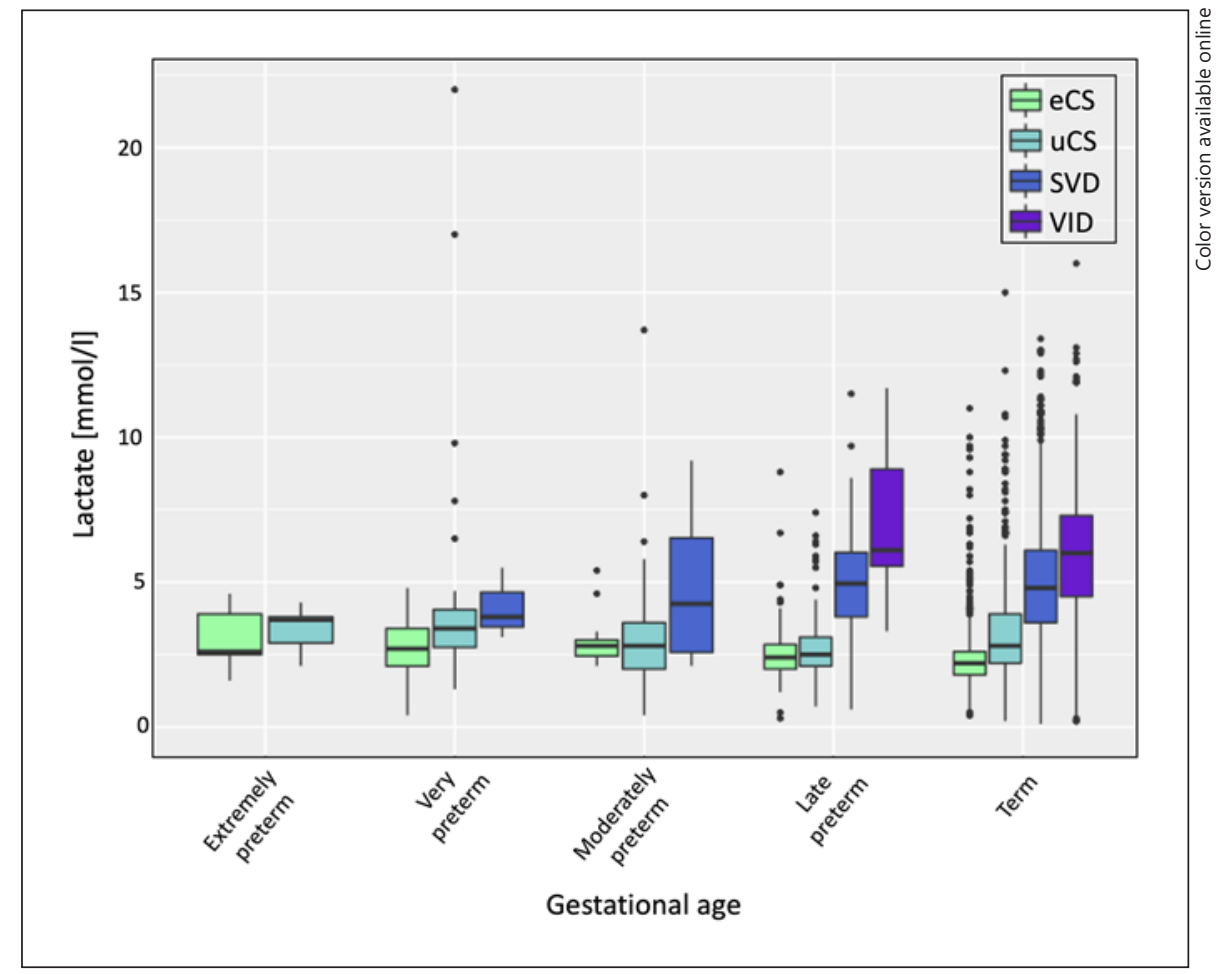

Healthy term infants are not regularly examined by a pediatrician after birth. In this large observational study, healthy infants had median lactate values of approximately $3.5 \mathrm{mmol} / \mathrm{L}$, and the 97 th percentile was $9 \mathrm{mmol} / \mathrm{L}$, indicating that some infants can recuperate well from perinatal stress if their transition to extrauterine life after birth is smooth. However, it has to be noted that some infants may deteriorate further after birth, emphasizing the necessity for a thorough clinical assessment of infants with acidotic metabolism during labor. Arterial cord lactate of infants admitted to the neonatal unit was similar to values of healthy infants. As there are various reasons for admission to the NICU, this finding demonstrates further that lactate values alone are insufficient to guide neonatal interventions, and laboratory evaluations need to be accompanied by a thorough clinical examination.

This study has several limitations: First, in a retrospective observational study, it is impossible to draw causal conclusions. In the absence of clear guidelines, we speculate that clinical consequences to lactate values were little (except for $\mathrm{pH}$ values $<7.00$ ), thus strengthening the value of this study. There are various perinatal factors contributing to lactate levels in newborns. However, the description of lactate values in a large dataset provides detailed reference ranges which will help clinicians to guide decision-making and interventions irrespective of the under- 
lying cause of elevated lactate levels. Second, the number of infants in separate gestational age groups was limited, particularly for extremely and very preterm infants. Therefore, we pooled the data by generally acknowledged age groups to increase reliability and clinical usability. Also, percentiles generated using this dataset may be most relevant for more mature infants (i.e., late preterm and term infants) which can be cared for on the regular postnatal ward. For these groups, the number of infants is sufficient to provide reliable results. Third, we only had general consent present for just over half of all infants born during the study period. While a higher number of included infants would have been preferable, there is no reason to assume systematic error based on the presence of a general consent. Fourth, this was a single-center study, and we cannot be certain that values can be extrapolated to other departments due to differing guidelines. Fifth, time of cord clamping was not recorded in our hospital. As the general relationship between cord clamping and arterial cord lactate has already been described [13, 14 ], our study now complements previous data by showing variations in lactate values across different modes of delivery. Finally, we did not assess clinical outcomes such as short- and long-term neurological outcome or mortality. The association of lactate with short-term neurological outcome has already been demonstrated [7], and the scope of this study was to provide reference ranges of lactate values across gestational age and modes of delivery.

\section{Conclusion}

In this retrospective observational study, we evaluated lactate values across modes of delivery and gestational ages. Both factors contribute to lactate levels with highest values occurring in instrumental vaginal deliveries and between 39 and 41 weeks gestational age. Based on these observations, we provide detailed reference ranges for clinical use.

\section{Acknowledgments}

We thank mothers and patients as well as staff at the University Hospital Zurich.

\section{Statement of Ethics}

This study protocol was reviewed and approved by the Cantonal Ethics Committee of the Canton Zurich, Approval No. KEK2021-00039. Mothers of all infants included in this study provided a written informed consent to allow use of their clinical and laboratory data for research purposes.

\section{Conflict of Interest Statement}

The authors have no conflicts of interest to declare.

\section{Funding Sources}

This study was supported by a Start-Up Grant of the European Society for Pediatric Research (to V.D.G.). The funding sources had no role in data analysis or writing and editing the manuscript.

\section{Author Contributions}

V.D.G. and J.R.F. conceived the idea and conceptualized the manuscript. V.D.G. performed data analysis and wrote the first draft of the manuscript. R.Z. and D.B. contributed to data interpretation with essential intellectual input. J.R.F. supervised the project. All authors contributed to manuscript writing and editing.

\section{Data Availability Statement}

De-identified individual participant data and statistical analysis codes are available from 3 months to 5 years following article publication to researchers who provide a methodologically sound proposal, with approval by an independent review committee ("learned intermediary"). Proposals should be directed to vincent. gaertner@usz.ch to gain access. Data requestors will need to sign a data access or material transfer agreement approved by USZ. Twitter: @NewbornZurich.

\section{References}

1 Kitlinski ML, Källén K, Marsál K, Olofsson P. Gestational age-dependent reference values for $\mathrm{pH}$ in umbilical cord arterial blood at term. Obstet Gynecol. 2003 Aug;102(2):33845.

2 Cowley NJ, Owen A, Bion JF. Interpreting arterial blood gas results. BMJ. 2013 Jan 16;346: f16.

3 Malin GL, Morris RK, Khan KS. Strength of association between umbilical cord $\mathrm{pH}$ and perinatal and long term outcomes: systematic review and meta-analysis. BMJ. 2010 May 13; 340:c1471.

4 Wiberg N, Källén K, Herbst A, Olofsson P. Relation between umbilical cord blood $\mathrm{pH}$, base deficit, lactate, 5-minute Apgar score and development of hypoxic ischemic encephalopathy. Acta Obstet Gynecol Scand. 2010 Oct 1;89(10):1263-9.

5 Tuuli MG, Stout MJ, Shanks A, Odibo AO, Macones GA, Cahill AG. Umbilical cord arterial lactate compared with $\mathrm{pH}$ for predicting neonatal morbidity at term. Obstet Gynecol. 2014 Oct;124(4):756-61.

6 Neacsu A, Herghelegiu C, Voinea S, Dimitriu M, Ples L, Bohiltea R, et al. Umbilical cord lactate compared with $\mathrm{pH}$ as predictors of intrapartum asphyxia. Exp Ther Med. 2021;21(1):80.

7 Allanson ER, Waqar T, White C, Tunçalp Ö, Dickinson JE. Umbilical lactate as a measure of acidosis and predictor of neonatal risk: a systematic review. BJOG. 2017 Mar;124(4): 584-94.
Umbilical Artery Lactate Reference Values
Neonatology 2021;118:609-616 DOI: $10.1159 / 000518748$ 
8 Westgren M, Divon M, Horal M, Ingemarsson I, Kublickas M, Shimojo N, et al. Routine measurements of umbilical artery lactate levels in the prediction of perinatal outcome. Am J Obstet Gynecol. 1995 Nov;173(5):1416-22.

9 Wiberg N, Källén K, Herbst A, Åberg A, Olofsson P. Lactate concentration in umbilical cord blood is gestational age-dependent: a population-based study of 17,867 newborns. BJOG. 2008 May 1;115(6):704-9.

10 Zanardo V, Mari G, de Luca F, Scambia G, Guerrini P, Straface G. Lactate in cord blood and its relation to fetal gluconeogenesis in at term deliveries. Early Hum Dev. 2015 Mar; 91(3):165-8.

11 Toffaletti J, Hammes ME, Gray R, Lineberry B, Abrams B. Lactate measured in diluted and undiluted whole blood and plasma: comparison of methods and effect of hematocrit. Clin Chem. 1992 Dec 1;38(12):2430-4.

12 Wiberg N, Källén K, Olofsson P. Physiological development of a mixed metabolic and respiratory umbilical cord blood acidemia with advancing gestational age. Early Hum Dev. 2006 Sep;82(9):583-9.
13 Giovannini N, Crippa BL, Denaro E, Raffaeli G, Cortesi V, Consonni D, et al. The effect of delayed umbilical cord clamping on cord blood gas analysis in vaginal and caesareandelivered term newborns without fetal distress: a prospective observational study. BJOG. 2020;127(3):405.

14 Wiberg N, Källén K, Olofsson P. Delayed umbilical cord clamping at birth has effects on arterial and venous blood gases and lactate concentrations. BJOG. 2008 May;115(6):697703.

15 Nordström L, Marcus C, Persson B, Shimojo $\mathrm{N}$, Westgren $\mathrm{M}$. Lactate in cord blood and its relationship to $\mathrm{pH}$ and catecholamines in spontaneous vaginal deliveries. Early Hum Dev. 1996 Sep 20;46(1-2):97-104.

16 McGillick EV, Lee K, Yamaoka S, Te Pas AB, Crossley KJ, Wallace MJ, et al. Elevated airway liquid volumes at birth: a potential cause of transient tachypnea of the newborn. J Appl Physiol. 2017 Nov 1;123(5):1204-13.
17 Bailit JL, Gregory KD, Reddy UM, GonzalezQuintero VH, Hibbard JU, Ramirez MM, et al. Maternal and neonatal outcomes by labor onset type and gestational age. Am J Obstet Gynecol. 2010 Mar;202(3):245.e1-12.

18 Wellmann S, Manegold-Brauer G, Fischer T, Schäffer L, Gaertner VD, Malfertheiner SF, et al. Improving neonatal and maternal outcome by inducing mild labor before elective cesarean section: the lacarus randomized controlled trial. Neonatology. 2021:116-21.

19 Operative vaginal birth: ACOG practice bulletin, number 219. Obstet Gynecol. 2020 Apr; 135(4):e149-59.

20 Zipori Y, Grunwald O, Ginsberg Y, Beloosesky R, Weiner Z. The impact of extending the second stage of labor to prevent primary cesarean delivery on maternal and neonatal outcomes. Am J Obstet Gynecol. 2019; 220(2):191.e1-7.

21 Bowe S, Staff AC, Sugulle M. Gestational age reference ranges for umbilical cord blood lactate: an external validation study of post-date pregnancies. Acta Obstet Gynecol Scand. 2020;99(11):1430-3.

22 Kraut JA, Madias NE. Lactic acidosis. N Engl J Med. 2014 Dec 11;371(24):2309-19. 